\title{
Survival benefit of radiotherapy on patients with early-stage extranodal nasal-type natural killer/T-cell lymphoma: an analysis of the surveillance epidemiology and end results database
}

\author{
Shi-Long Zhang ${ }^{1}$, Zhi-Ming Wang ${ }^{2}$, Yi-Feng Sun ${ }^{1}$ and Jian-Min $X_{u^{1}}$ \\ ${ }^{1}$ Department of Hematology, Zhongshan Hospital, Fudan University, Shanghai, 200032, China \\ ${ }^{2}$ Department of Medical Oncology, Zhongshan Hospital, Fudan University, Shanghai, 200032, China \\ Correspondence to: Jian-Min Xu, email: 18221147686@163.com
}

Keywords: extranodal natural killer/T-cell lymphoma; radiotherapy; surveillance epidemiology and end results; prognostic factors

Received: July 31, $2017 \quad$ Accepted: November 13, $2017 \quad$ Published: January 03, 2018

Copyright: Zhang et al. This is an open-access article distributed under the terms of the Creative Commons Attribution License 3.0 (CC BY 3.0), which permits unrestricted use, distribution, and reproduction in any medium, provided the original author and source are credited.

\section{ABSTRACT}

Background: Extranodal natural killer/T-cell lymphoma (ENKTL) is a rare malignant lymphoid malignancy. The survival benefit of radiotherapy (RT) in earlystage ENKTL patients remains controversial. This study was conducted to investigate the prognostic factors, and evaluate survival benefit of RT in early-stage ENKTL patients.

Materials and Methods: Early-stage ENKTL patients between 2004 and 2013 were searched from the Surveillance Epidemiology and End Results (SEER) database. Clinical characteristics including sex, age at diagnosis, race, marital status, era of diagnosis, histology, Ann Arbor stage and RT were summarized. Kaplan-Meier and multivariate Cox proportional hazards regression analysis were performed to investigate the independent prognostic factors for early-stage ENKTL patients. Subgroup analysis was conducted to evaluate the benefit of $R T$ on overall survival (OS) and cancer specific survival (CSS) based on different Ann Arbor stages.

Results: Patients with early-stage ENKTL were more likely to be younger, present with B symptoms. RT was more likely used for younger patients and those presented with B symptoms. Kaplan-Meier and multivariate Cox regression analysis showed that Ann Arbors stage and RT were the independent prognostic factors for survival ( $p<$ 0.05). And RT was associated with a lower risk of mortality for OS and CSS. Subgroup analysis based on different Ann Arbor stages showed that RT can decrease $66 \%$ risks of mortality in Stage I and more than $60 \%$ risks of mortality in Stage II $(p<0.005)$.

Conclusions: RT could contribute to significant survival benefit among early-stage ENKTL patients. Significant survival benefit of RT still remained in any disease stage.

\section{INTRODUCTION}

Extranodal nasal-type natural killer/T-cell lymphoma (ENKTL) is a rare subtype of non-Hodgkin's lymphoma, which is prevalently distributed in East Asia and South America [1,2]. ENKTL occurs predominantly in the nasal cavity and nasal side area and the disease is highly aggressive, is not sensitive to chemotherapy and has poor prognosis. The 5-year overall survival (OS) ranges from $40 \%$ to $90 \%$ for early-stage patients [3-7].
ENKTL is closely connected with the Epstein-Barr virus (EBV) infection, which assists in the diagnosis of ENKTL [8]. The characteristic surface markers of $\mathrm{NK} / \mathrm{T}$ cells and the specific genetic mutations can also contribute to its diagnosis. Due to unique biological behavior and various clinical manifestations [9], ENKTL has been recognized as a novel classification of lymphoid neoplasms by the World Health Organization [10].

Although several studies have explored the treatment of ENKTL in recent years, the optimal treatment 
is still unclear [11]. Currently, radiotherapy (RT) is the most widely used treatment for patients with early-stage ENKTL. Depressingly, the clinical efficacy of RT reported was controversial [6, 9, 12-15]. Few prospectively designed, randomized and controlled clinical trials have been conducted to explore the survival benefit of RT for early-stage ENKTL patients and current evidence mainly relies on retrospective studies and series case reports with small samples. Additionally, most of them were conducted in Asian countries [6, 9, 12-14, 16-20]. In view of above, we conducted a population-based analysis of patients with early-stage ENKTL from the Surveillance, Epidemiology, and End Results (SEER) database to evaluate the survival benefit associated with RT and investigate the prognostic factors for early-stage ENKTL patients.

\section{RESULTS}

\section{The baseline of patient characteristics}

A total of 348 patients with Stage I and II ENKTL from 2004 to 2013 were found eligible for our analysis, including $221(63.51 \%)$ patients in RT group and 127 (36.49\%) in no-RT group. Demographic and pathologic information are summarized in Table 1. A total of $123(35.34 \%)$ patients were over 60 years old $(p=0.025)$ and $232(66.67 \%)$ of them were male $(p=0.665)$. For patients younger than 60 years old or presented with B symptoms, they were more likely to receive RT $(p<0.05)$. The patients in two groups showed no significant variances with regards to other baseline characteristics including sex, race, marital status, era of diagnosis, histology and Ann Arbor stage.

\section{Kaplan-Meier analysis for the effect of clinical characteristics on OS and CSS}

Kaplan-Meier analysis was performed to calculate the OS and CSS of the early-stage ENKTL patients (Table 2). The OS (Figure 1) and CSS (Figure 2) were significantly longer in RT group than that in no-RT group (log-rank test $p<0.001$ ), which was in favor of RT. What's more, the median OS of RT group (93.0 months, 95\% CI: 56.0-NA months) was much longer than that of no-RT group (10.0 months, 95\% CI: 7.0 22.0 months). Ann Arbor stage was significantly associated with OS (Figure 3) and CSS (Figure 4). Sex, age at diagnosis, race, marital status, era of diagnosis, histology and B symptoms were found no significant associations with survival $(p>0.05)$.

\section{Multivariate Cox proportional hazards regression analysis for identification of prognostic factors in patients with early-stage ENKTL}

When we adjusted all clinical factors in the multivariate analysis, Ann Arbor stage and RT were recognized as independent prognostic factors for OS and
CSS among early-stage ENKTL patients (Table 3). In the terms of OS, the mortality risks of the patients in RT group decreased more than $60 \%$ compared with that in no-RT group $(\mathrm{HR}=0.39,95 \%$ CI $0.28-0.54, p<0.001)$. For CSS, RT was still identified as a protective factor with a much lower hazards of mortality $(\mathrm{HR}=0.40,95 \%$ CI $0.28-0.58, p<0.001)$. Ann Arbor stage was also an independent prognostic factor but negatively associated with OS and CSS.

\section{Subgroup analysis of the effect of RT on OS and CSS based on Ann Arbor stage}

Previous studies have well demonstrated that Ann Arbor stage is an independent prognostic factor for ENKTL patients $[9,17,21,22]$. Thus, in order to further explore the effect of RT on OS and CSS, we conducted a subgroup analysis based on different Ann Arbor stages. Results were summarized in Table 4. Interestingly, RT could significantly improve OS and CSS in Stage I (OS, HR: 0.34, 95\% CI: 0.22-0.51, $p<0.001$; CSS, HR: 0.38, 95\% CI: $0.23-0.60, p<0.001$, respectively) and Stage II (OS, HR: 0.37, 95\% CI: 0.20-0.67, $p=0.001$; CSS, HR: $0.31,95 \%$ CI: $0.16-0.60, p<0.001$, respectively).

\section{DISCUSSION}

Extranodal natural killer/T-cell lymphoma, nasal type (ENKTL) is rare, aggressive and poor prognostic. The disease is relatively common in Asia and South America but rare in Western countries . And that results in few large sample clinical trials of ENKTL. To date, there has been no standard treatment available for ENKTL. The current treatment includes chemotherapy, RT alone, chemotherapy after RT, RT after chemotherapy or concurrent chemoradiotherapy [19, 23, 24]. Available evidence suggests that RT is preferred for early-stage NKTCL patients. Li et al. [25] reported that RT alone could significantly improve the survival outcomes of patients with Stage I ENKTL. In their study, the complete response was $95.4 \%(83 / 87)$ and partial response $2.3 \%$ $(2 / 87)$. For all patients, the 5 -year OS of $80 \%$, progressionfree survival of $69 \%$, and local control of $93 \%$ were observed. More recently, Yang et al. [26] conduct a largescale retrospective analysis of Stage I ENKTL patients and they are all given high-dose extended-field RT with a median radiation dose of 50 Gy (range, 20-65 Gy). The overall response to RT arrived to $97.7 \%(85 / 87)$ patients in a short time, recommending $50 \mathrm{~Gy}$ as the optimal dose for patients with early-stage disease.

However, due to the rarity of ENKTL and few large sample randomized controlled trials, the role of RT is still not well defined. Fortunately, the Surveillance, Epidemiology, and End Results (SEER) Program has been established and the relevant information of cancer patients is collected from large numbers of cancer registries which 
Table 1: Baseline characteristics according to RT and no-RT group

\begin{tabular}{|c|c|c|c|c|}
\hline \multirow{2}{*}{ Characteristic } & Total (\%) & RT (\%) & no-RT (\%) & $\overline{p \text { value }}$ \\
\hline & $348(100)$ & $221(63.51)$ & $127(36.49)$ & \\
\hline Sex & & & & 0.665 \\
\hline Female & $116(33.33)$ & $76(21.84)$ & 40 (11.49) & \\
\hline Male & $232(66.67)$ & 145 (41.67) & $87(25.00)$ & \\
\hline Age at diagnosis & & & & 0.025 \\
\hline$<60$ & $225(64.66)$ & $153(43.97)$ & $72(20.69)$ & \\
\hline$>=60$ & $123(35.34)$ & 68 (19.54) & $55(15.80)$ & \\
\hline Race & & & & 0.118 \\
\hline White & $246(70.69)$ & $160(45.98)$ & $86(24.71)$ & \\
\hline Black & $23(6.61)$ & $10(2.87)$ & $13(3.7)$ & \\
\hline Asian & $79(22.70)$ & $51(14.66)$ & $28(8.05)$ & \\
\hline Marital status & & & & 0.242 \\
\hline Married & $210(60.34)$ & 139 (39.94) & $71(20.40)$ & \\
\hline Unmarried & $138(39.66)$ & $82(16.09)$ & $56(23.56)$ & \\
\hline Era of diagnosis & & & & 0.451 \\
\hline 2004-2008 & $162(46.55)$ & $99(28.45)$ & $63(18.10)$ & \\
\hline 2009-2013 & $186(53.45)$ & $122(35.06)$ & 64 (18.39) & \\
\hline Histology & & & & 0.200 \\
\hline NK cell & $240(68.97)$ & $153(43.97)$ & $87(25.00)$ & \\
\hline $\mathrm{T}$ cell & $90(25.86)$ & $60(17.24)$ & $30(8.62)$ & \\
\hline Other/unknown & $18(5.17)$ & $8(2.30)$ & $10(2.87)$ & \\
\hline Ann Arbor stage & & & & 0.983 \\
\hline I & $240(68.97)$ & $153(43.97)$ & $87(25.00)$ & \\
\hline II & $108(31.03)$ & 68 (19.54) & 40 (11.49) & \\
\hline B symptoms & & & & 0.003 \\
\hline Present & $191(54.89)$ & $133(38.22)$ & $58(16.67)$ & \\
\hline Absent & 97 (27.87) & $61(17.53)$ & $36(10.34)$ & \\
\hline Unknown & $60(17.24)$ & $27(7.76)$ & $33(9.48)$ & \\
\hline
\end{tabular}

SEER 2004-2013 $(n=348)$.

covers 9,0468 population, accounting for $28 \%$ in the United States . With large clinical information of cancer patients, it is a favorable tool to investigate rare carcinoma. In this study, we used SEER database to retrospectively evaluate the survival benefit of RT on patients with earlystage ENKTL. Since great advancements have been achieved in modern radiotherapy and the applications of rituximab in the last decade for lymphoma [27], we restricted the era of diagnosis from 2004 to 2013 to lower the risk of potential confusion. The characteristics of ENKTL patients used in our study included sex, age at diagnosis, race, marital status, era of diagnosis, histology, Ann Arbor stage, B symptoms and RT. We found RT was more likely to be used in patients younger than 60 years old and those presented with B symptoms. Kaplan-Meier analysis showed that OS was associated with Ann Arbors stage and RT $(p<0.05)$, but not associated with sex, age at diagnosis, race, era of diagnosis, histology and B symptoms $(p>0.05)$. It was consistent with the previous literature reports [12, 21, 22, 28-32]. Multivariate Cox regression analysis revealed that Ann Arbor stage and RT were both significantly associated with OS and CSS $(p<0.05)$. Because RT contributed to significant survival benefits for both OS and CSS, we illustrated OS in the following discussion. Patients had a higher risks of mortality in Stage II (HR 1.63, 95\% CI 1.17-2.27, $p=0.004$ ) compared with those in Stage I. Interestingly, no significant mortality risks difference were observed in age at diagnosis, era of diagnosis and histology $(p>0.05)$. This may be associated with the rapid progression, quick 


$$
\text { Strata }+ \text { RT }+\cdot \cdot \text { no-RT }
$$
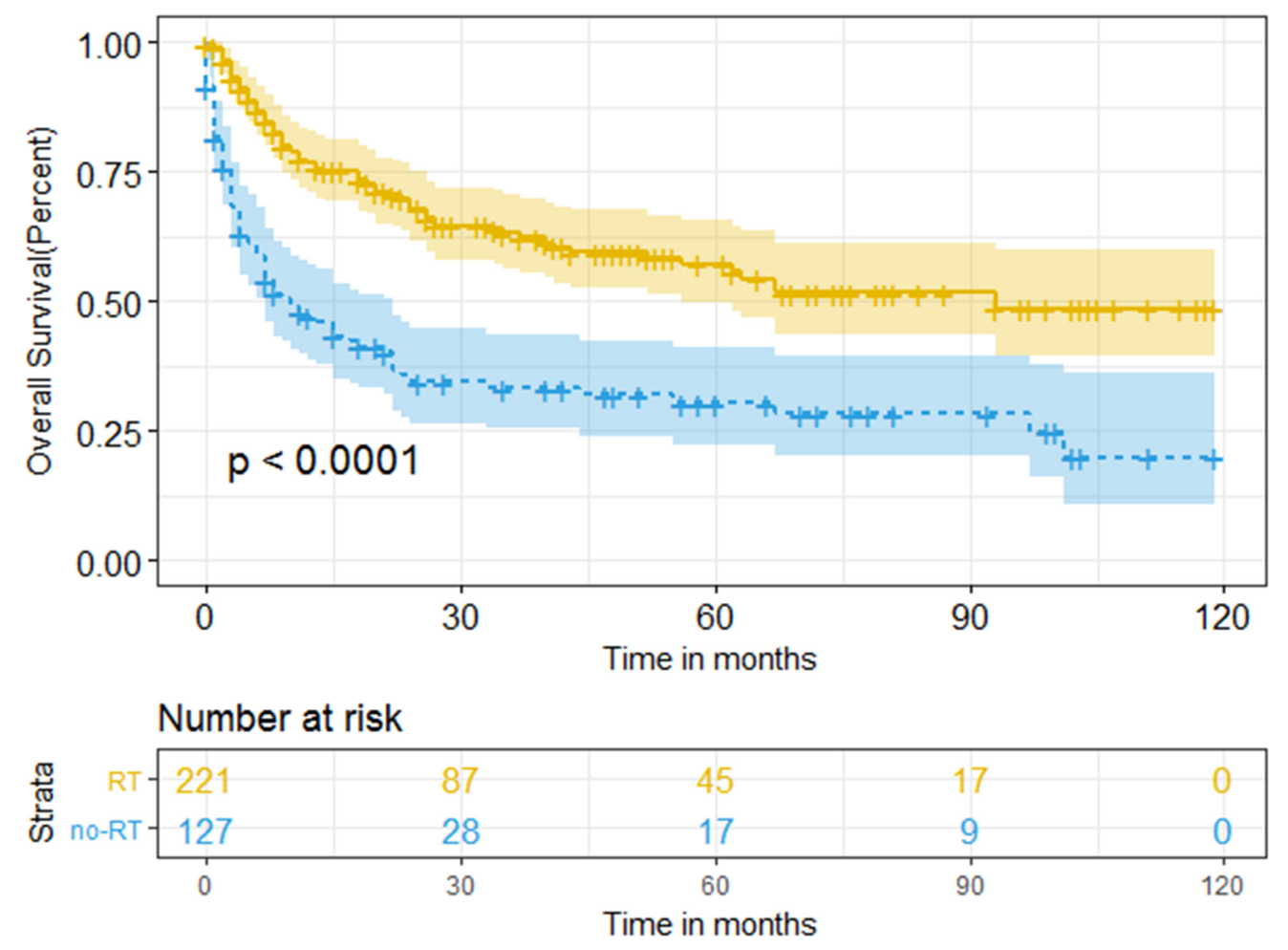

Figure 1: Kaplan-Meier curves of the overall survival in patients according to RT and no-RT.
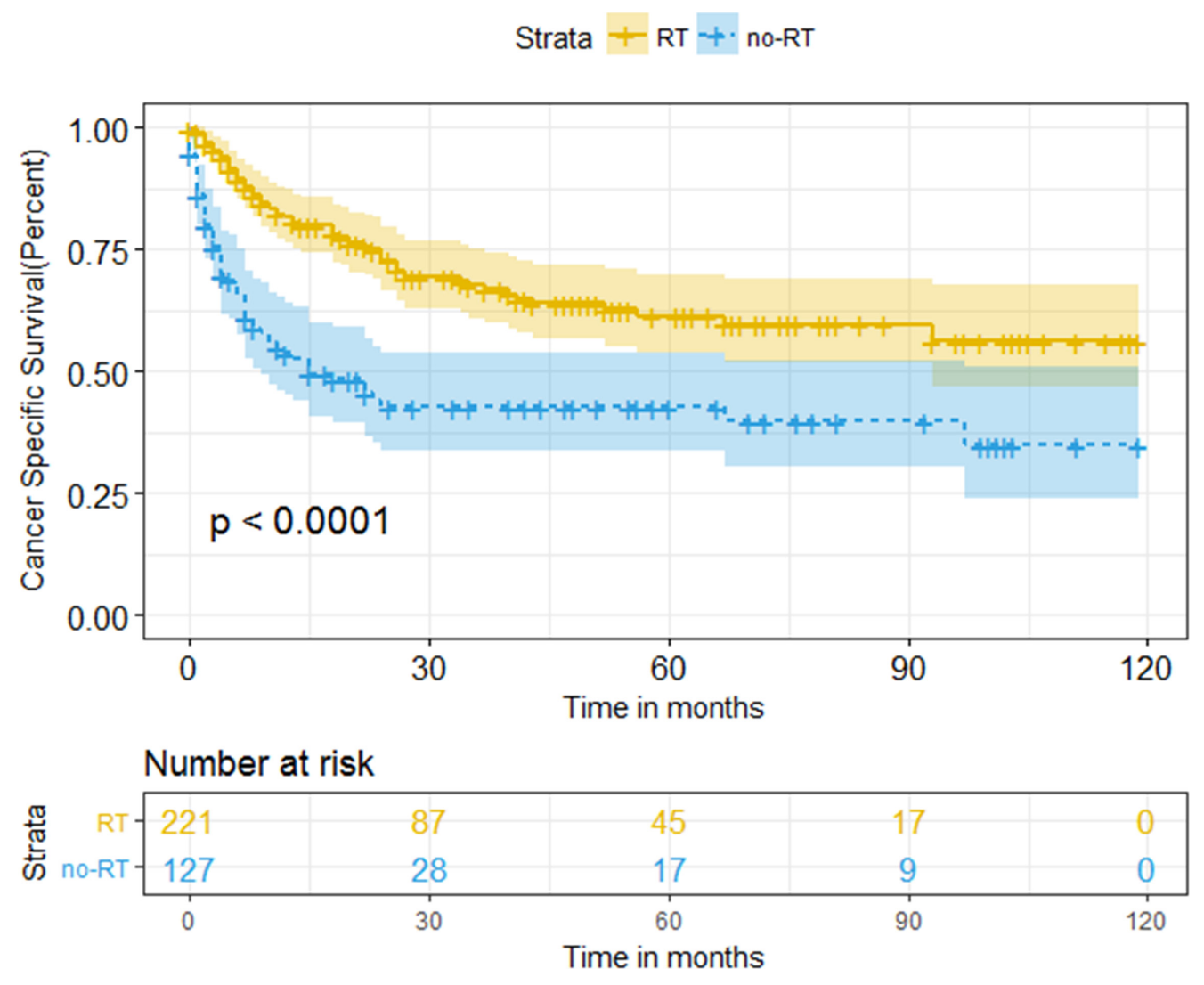

Figure 2: Kaplan-Meier curves of the cancer specific survival in patients according to RT and no-RT. 
Table 2: Kaplan-Meier analysis and multivariate cox proportional hazards regression analysis of OS for early-stage NKTL patients

\begin{tabular}{|c|c|c|c|c|c|}
\hline \multirow{2}{*}{ Variables } & \multicolumn{2}{|c|}{ Univariate analysis } & \multicolumn{3}{|c|}{ Multivariate analysis } \\
\hline & $\log \operatorname{rank} \chi^{2}$ & $p$ value & HR & $95 \% \mathrm{CI}$ & $p$ value \\
\hline$\overline{\text { Sex }}$ & 0.9 & 0.333 & & & \\
\hline Female & & & Reference & & \\
\hline Male & & & 1.08 & $0.77-1.53$ & 0.621 \\
\hline Age at diagnosis & 2.9 & 0.086 & & & \\
\hline$<60$ & & & Reference & & \\
\hline$>=60$ & & & 1.04 & $0.96-1.58$ & 0.039 \\
\hline Race & 0.5 & 0.767 & & & \\
\hline White & & & Reference & & \\
\hline Black & & & 0.89 & $0.48-1.67$ & 0.727 \\
\hline Asian & & & 0.89 & $0.61-1.30$ & 0.552 \\
\hline Marital status & 0 & 0.987 & & & \\
\hline Married & & & Reference & & \\
\hline Unmarried & & & 1.01 & $0.72-1.42$ & 0.959 \\
\hline Era of diagnosis & 1.7 & 0.195 & & & \\
\hline 2004-2008 & & & Reference & & \\
\hline 2009-2013 & & & 0.80 & $0.56-1.15$ & 0.234 \\
\hline Histology & 1.3 & 0.528 & & & \\
\hline NK cell & & & Reference & & \\
\hline $\mathrm{T}$ cell & & & 1.06 & $0.73-1.54$ & 0.753 \\
\hline Other/unknown & & & 1.01 & $0.52-1.95$ & 0.989 \\
\hline Ann Arbor stage & 9.4 & 0.002 & & & \\
\hline I & & & Reference & & \\
\hline II & & & 1.63 & $1.17-2.27$ & 0.004 \\
\hline B symptoms & 7.2 & 0.536 & & & \\
\hline Absent & & & Reference & & \\
\hline Present & & & 1.09 & $0.73-1.61$ & 0.659 \\
\hline Unknown & & & 1.01 & $0.64-1.57$ & 0.987 \\
\hline Radiotherapy, RT & 37.7 & $<0.001$ & & & \\
\hline No RT & & & Reference & & \\
\hline Yes & & & 0.39 & $0.28-0.54$ & $<0.001$ \\
\hline
\end{tabular}

Abbreviations: $\mathrm{HR}=$ hazard ratio; $\mathrm{CI}=$ confidence interval.

SEER 2004-2013 $(n=348)$.

recurrence and poor prognosis of ENKTL. Results of subgroup analysis indicated that RT can decrease $72.1 \%$ risks of mortality in Stage I (HR 0.34, 95\% CI 0.22-0.51, $p<0.001)$, and more than $60 \%$ risks of mortality in Stage II (HR 0.37, 95\% CI $0.20-0.67, p<0.001$ ).

Though the present study was large populationbased, the results should be interpreted with caution since it had several limitations. First, SEER-18 cohort database does not have information about RT dosage, the timing of
$\mathrm{RT}$, and side effects of RT, which limits us to investigate the definite advantage of RT irrespective of diseasespecific chemotherapies or better supportive care. Second, RT group had a higher proportion of younger patients than the older $(43.97 \%$ vs $19.54 \%, p=0.025)$. Generally, the younger may maintain good physical condition with less comorbidities, which may well contribute to better OS and CSS [33]. Third, the SEER-18 cohort database lacks the prognostic information (IPI score, EBV-DNA, Ki-67, 
Table 3: Kaplan-Meier analysis and multivariate cox proportional hazards regression analysis of CSS for early-stage NKTL patients

\begin{tabular}{|c|c|c|c|c|c|}
\hline \multirow{2}{*}{ Variables } & \multicolumn{2}{|c|}{ Kaplan-Meier analysis } & \multicolumn{3}{|c|}{ Multivariate analysis } \\
\hline & $\log \operatorname{rank} \chi^{2}$ & $p$ value & HR & $95 \%$ CI & $p$ value \\
\hline Sex & 0.9 & 0.333 & & & \\
\hline Female & & & Reference & & \\
\hline Male & & & 1.01 & $0.69-1.48$ & 0.951 \\
\hline Age at diagnosis & 0.5 & 0.482 & & & \\
\hline$<60$ & & & Reference & & \\
\hline$>=60$ & & & 1.11 & $0.75-1.66$ & 0.594 \\
\hline Race & 2.8 & 0.249 & & & \\
\hline White & & & Reference & & \\
\hline Black & & & 1.19 & $0.62-2.33$ & 0.595 \\
\hline Asian & & & 1.1 & $0.73-1.67$ & 0.637 \\
\hline Marital status & 1 & 0.307 & & & \\
\hline Married & & & Reference & & \\
\hline Unmarried & & & 0.77 & $0.52-1.14$ & 0.195 \\
\hline Era of diagnosis & 2.1 & 0.146 & & & \\
\hline 2004-2008 & & & Reference & & \\
\hline 2009-2013 & & & 0.87 & $0.56-1.36$ & 0.518 \\
\hline Histology & 4.6 & 0.103 & & & \\
\hline NK cell & & & Reference & & \\
\hline $\mathrm{T}$ cell & & & 1.27 & $0.84-1.93$ & 0.261 \\
\hline Other/unknown & & & 1.24 & $0.61-2.53$ & 0.543 \\
\hline Ann Arbor Stage & 8.8 & 0.003 & & & \\
\hline I & & & Reference & & \\
\hline II & & & 1.67 & $1.16-2.42$ & 0.006 \\
\hline B symptoms & 0.1 & 0.949 & & & \\
\hline Absent & & & Reference & & \\
\hline Present & & & 0.87 & $0.56-1.36$ & 0.659 \\
\hline Unknown & & & 0.81 & $0.49-1.36$ & 0.987 \\
\hline Radiotherapy, RT & 26.2 & $<0.001$ & & & \\
\hline No RT & & & Reference & & \\
\hline Yes & & & 0.4 & $0.28-0.58$ & $<0.001$ \\
\hline
\end{tabular}

Abbreviations: $\mathrm{HR}=$ hazard ratio; $\mathrm{CI}=$ confidence interval.

SEER 2004-2013 $(n=348)$.

lactate dehydrogenase (LDH) and so on), which are well documented independent prognostic factors for survival outcome $[34,35]$. For example, the EBV-DNA copy numbers are associated with tumor burden and can predict independently the outcomes of ENKTL patients [8]. Finally, the present research had its inherent limitations and several bias since it was a retrospective study. Further prospective studies are needed to explore in depth. Despite the potential limitations, there were better OS and CSS in

ENKTL patients who underwent RT, which was enough to demonstrate the survival benefit of RT in early-stage ENKTL patients.

One should be noted that chemotherapy regimens were not brought into the survival analysis in our study. It was as a direct result of missing chemotherapy records in the SEER-18 cohort database. However, as we mentioned previously, ENKTL is an uncommon disease and its chemotherapy regimens still remain controversial. 
Strata + Stage $1+\cdot$ Stage II
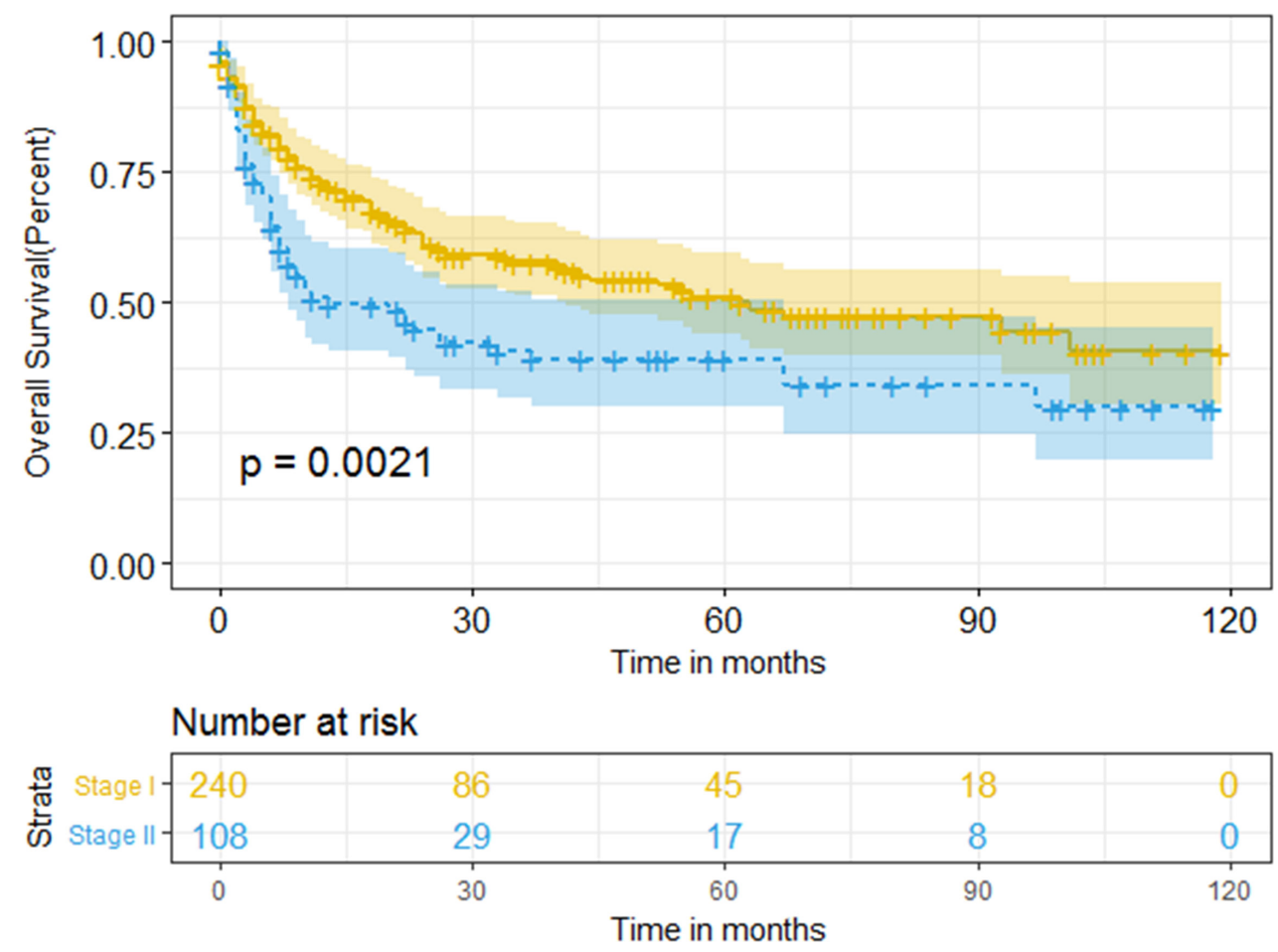

Figure 3: Kaplan-Meier curves of the overall survival in patients according to Ann Arbor stage.
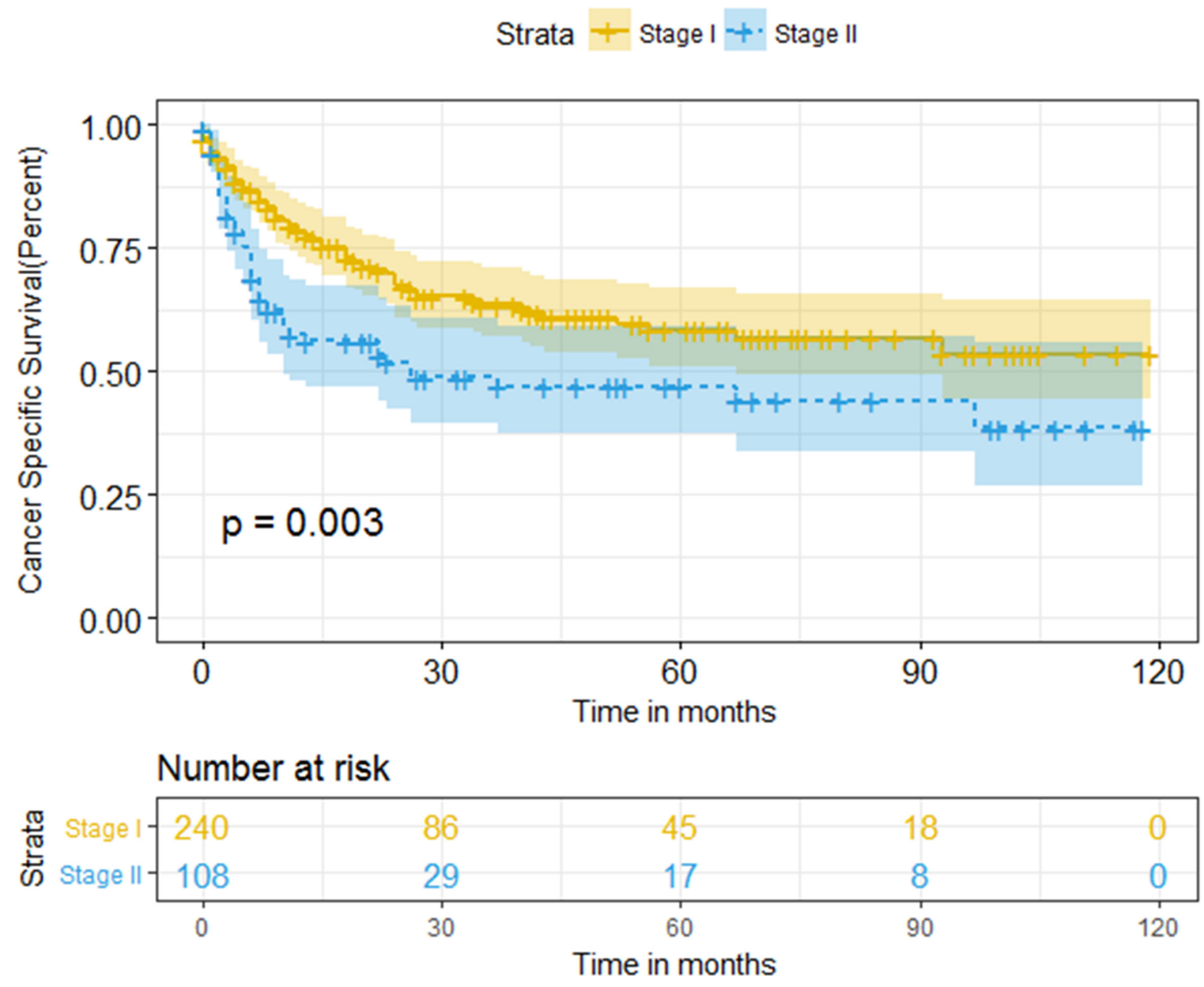

Figure 4: Kaplan-Meier curves of the cancer specific survival in patients according to Ann Arbor stage. 
Table 4: Multivariate analysis of RT on overall and cancer specific survival based on Ann Arbor stage

\begin{tabular}{lcccc}
\hline Characteristic & OS HR $(\mathbf{9 5 \%}$ CI $)$ & $\boldsymbol{p}$ value & CSS HR(95\% CI) & $p$ value \\
\hline Stage I & & & & \\
no-RT & Reference & & Reference & \\
RT & $0.34(0.22-0.51)$ & $<0.001$ & $0.38(0.23-0.60)$ & $<0.001$ \\
Stage II & & & \\
no-RT & Reference & & Reference & \\
RT & $0.37(0.20-0.67)$ & 0.001 & $0.31(0.16-0.60)$ & $<0.001$ \\
\hline
\end{tabular}

Abbreviations: $\mathrm{HR}=$ hazard ratio; $\mathrm{CI}=$ confidence interval.

For the last decades, no effective novel drug has been available [36], and the anthracycline-based chemotherapy regimens that have high similarity are recommended for most ENKTL patients [37, 38]. Furthermore, the addition of chemotherapy to RT does not change the survival outcomes of patients with early-stage ENKTL [24, 25, 39-44]. Hence, we have reasons to assume that lack of chemotherapy information has little impact on the final conclusions of our study.

In conclusion, RT could contribute to significant survival benefit among early-stage ENKTL patients. Ann Arbor stage and RT were both independent prognostic factors for early-stage ENKTL patients . Ann Arbor stage was negatively associated with OS and CSS. RT was positively associated with OS and CSS. Subgroup analysis showed that survival benefit of RT still remained in any disease stage.

\section{MATERIALS AND METHODS}

\section{Data source and study variables}

The clinical data was extracted from SEER-18 cohort database [Incidence -SEER 18 Regs Research Data + Hurricane Katrina Impacted Louisiana Cases, Nov 2015 Sub (1973-2013 varying)] via the SEER *Stat 8.0.4 software (National Cancer Institute, Bethesda, MD) [45]. Because information on the $\mathrm{B}$ symptoms of lymphoma was not available until 2004, we restricted our study between 2004-2013. Referring to the International Classification of Diseases for Oncology, 3rd edition codes, we identify the ENKTL patients (9719/3). Next, we categorized patients into several cohorts based on sex (female, male), age at diagnosis $(<60$ years old, $>=60$ years old), race (white, black, Asian), marital status (married, unmarried), era of diagnosis (2004-2008, 2009-2013), histology (NK cell, T cell,other/unknown), B symptoms (absence, presence, unknown) and stage at diagnosis (stage I, stage II).

\section{Statistical analysis}

The statistical analysis was performed with R software (version 3.3.2). Baseline characteristics of patients were analyzed with Chi-squared test. Survival analysis was performed with Kaplan-Meier analysis and multivariable Cox proportional hazards regression analysis were conducted to evaluate whether clinical factors were associated with OS and CSS, respectively. The clinical factors contained sex, age at diagnosis, race, marital status, era of diagnosis, histology, Ann Arbor stage, B symptoms, and radiotherapy. Finally, subgroup analyses via Cox proportional hazards regression model were conducted based on different disease stages. All $p$-values were two-sided and the $p<0.05$ was considered statistically significant.

\section{Author contributions}

Shi-long Zhang, Zhi-ming Wang and Jian-min Xu conceived and designed the study. Shi-long Zhang, Zhiming Wang and Yi-feng Sun performed the analysis and wrote the main manuscript. Shi-long Zhang prepared the figures and tables. All of the authors reviewed the manuscript.

\section{ACKNOWLEDGMENTS}

The authors were grateful to the Surveillance, Epidemiology, and End Results (SEER) Program tumor registries for providing high quality open clinical materials for researchers worldwide.

\section{CONFLICTS OF INTEREST}

The authors declare that they have no conflicts of interest concerning this article.

\section{FUNDING}

The present study was supported by no funds.

\section{REFERENCES}

1. William BM, Armitage JO. International analysis of the frequency and outcomes of NK/T-cell lymphomas. Best Pract Res Clin Haematol. 2013; 26:23-32.

2. Au WY, Weisenburger DD, Intragumtornchai T, Nakamura S, Kim WS, Sng I, Vose J, Armitage JO, Liang R. Clinical 
differences between nasal and extranasal natural killer/Tcell lymphoma: a study of 136 cases from the International Peripheral T-Cell Lymphoma Project. Blood. 2009; 113:3931-3937.

3. Gill H, Liang RH, Tse E. Extranodal natural-killer/t-cell lymphoma, nasal type. Adv Hematol. 2010; 2010:627401.

4. Li CC, Tien HF, Tang JL, Yao M, Chen YC, Su IJ, Hsu SM, Hong RL. Treatment outcome and pattern of failure in 77 patients with sinonasal natural killer/T-cell or T-cell lymphoma. Cancer. 2004; 100:366-375.

5. Bi XW, Jiang WQ, Zhang WW, Huang JJ, Xia Y, Wang Y, Sun P, Li ZM. Treatment outcome of patients with advanced stage natural killer/T-cell lymphoma: elucidating the effects of asparaginase and postchemotherapeutic radiotherapy. Ann Hematol. 2015; 94:1175-1184.

6. Wang ZY, Li YX, Wang WH, Jin J, Wang H, Song YW, Liu QF, Wang SL, Liu YP, Qi SN, Fang H, Liu XF, Yu ZH. Primary radiotherapy showed favorable outcome in treating extranodal nasal-type NK/T-cell lymphoma in children and adolescents. Blood. 2009; 114:4771-4776.

7. Kim TM, Lee SY, Jeon YK, Ryoo BY, Cho GJ, Hong YS, Kim HJ, Kim SY, Kim CS, Kim S, Kim JS, Sohn SK, Song $\mathrm{HH}$, et al. Clinical heterogeneity of extranodal NK/T-cell lymphoma, nasal type: a national survey of the Korean Cancer Study Group. Ann Oncol. 2008; 19:1477-1484.

8. Gru AA, Haverkos BH, Freud AG, Hastings J, Nowacki NB, Barrionuevo C, Vigil CE, Rochford R, Natkunam Y, Baiocchi RA, Porcu P. The Epstein-Barr Virus (EBV) in T Cell and NK Cell Lymphomas: Time for a Reassessment. Curr Hematol Malig Rep. 2015; 10:456-467.

9. Li YX, Fang H, Liu QF, Lu J, Qi SN, Wang H, Jin J, Wang WH, Liu YP, Song YW, Wang SL, Liu XF, Feng XL, Yu ZH. Clinical features and treatment outcome of nasal-type NK/T-cell lymphoma of Waldeyer ring. Blood. 2008; 112:3057-3064.

10. Harris NL, Jaffe ES, Diebold J, Flandrin G, MullerHermelink HK, Vardiman J, Lister TA, Bloomfield CD. The World Health Organization classification of neoplastic diseases of the haematopoietic and lymphoid tissues: Report of the Clinical Advisory Committee Meeting, Airlie House, Virginia, November 1997. Histopathology. 2000; 36:69-86.

11. Kim TH, Kim JS, Suh YG, Cho J, Yang WI, Suh CO. The Roles of Radiotherapy and Chemotherapy in the Era of Multimodal Treatment for Early-Stage Nasal-Type Extranodal Natural Killer/T-Cell Lymphoma. Yonsei Med J. 2016; 57:846-854.

12. Yang Y, Zhu Y, Cao JZ, Zhang YJ, Xu LM, Yuan ZY, Wu JX, Wang W, Wu T, Lu B, Zhu SY, Qian LT, Zhang FQ, et al. Risk-adapted therapy for early-stage extranodal nasaltype NK/T-cell lymphoma: analysis from a multicenter study. Blood. 2015; 126:1424-1432; quiz 1517.

13. Xiong X, Cai Z, Yang J, Shu X. Efficacy of pegaspargase in extra nodal natural killer/T-cell lymphoma nasal type: A case report from China. J Cancer Res Ther. 2015; $11: 665$.
14. Jing XM, Zhang ZH, Wu P, Zhang SC, Ren YR, Xiong ZJ, Wei W, Luo L, Li L. Efficacy and tolerance of pegaspargase, gemcitabine and oxaliplatin with sandwiched radiotherapy in the treatment of newly-diagnosed extranodal nature killer (NK)/T cell lymphoma. Leuk Res. 2016; 47:26-31.

15. Hattori Y, Murai T, Iwata H, Uchiyama K, Mimura M, Kato E, Murata R, Shibamoto Y. Chemoradiotherapy for localized extranodal natural killer/T-cell lymphoma, nasal type, using a shrinking-field radiation strategy: multi-institutional experience. Jpn J Radiol. 2016; 34:292-299.

16. Zhang XX, Xie CH, Xu Y, Deng D, Zhao YH, Zou BW, Zhou L, Li M, Wang J, Liu WP, Huang MJ. Salvage treatment improved survival of patients with relapsed extranodal natural killer/t-cell lymphoma, nasal type. Int J Radiat Oncol Biol Phys. 2009; 74:747-752.

17. Ren X, Jia Q, Xiang G, Zhao Z, Xu K, Du W. [Clinical study of 34 patients with extranodal NK/T cell lymphomanasal type]. Lin Chung Er Bi Yan Hou Tou Jing Wai Ke Za Zhi. 2007; 21:361-362. [Article in Chinese].

18. Laskin JJ, Savage KJ, Voss N, Gascoyne RD, Connors JM. Primary paranasal sinus lymphoma: natural history and improved outcome with central nervous system chemoprophylaxis. Leuk Lymphoma. 2005; 46:1721-1727.

19. Huang MJ, Jiang Y, Liu WP, Li ZP, Li M, Zhou L, Xu Y, Yu CH, Li Q, Peng F, Liu JY, Luo F, Lu Y. Early or up-front radiotherapy improved survival of localized extranodal NK/T-cell lymphoma, nasal-type in the upper aerodigestive tract. Int J Radiat Oncol Biol Phys. 2008; 70:166-174.

20. Bi XW, Li YX, Fang H, Jin J, Wang WH, Wang SL, Liu YP, Song YW, Ren H, Dai JR. High-dose and extended-field intensity modulated radiation therapy for early-stage NK/T-cell lymphoma of Waldeyer's ring: dosimetric analysis and clinical outcome. Int J Radiat Oncol Biol Phys. 2013; 87:1086-1093.

21. Fang H, Jin J, Wang WH, Wang SL, Zhou LQ, Li YX. Prognostic factors and treatment outcomes for patients with stage II extranodal nasal-type natural killer/Tcell lymphoma of the upper aerodigestive tract. Leuk Lymphoma. 2014; 55:1832-1837.

22. Cai Q, Luo X, Zhang G, Huang H, Huang H, Lin T, Jiang W, Xia Z, Young KH. New prognostic model for extranodal natural killer/T cell lymphoma, nasal type. Ann Hematol. 2014; 93:1541-1549.

23. Guo Y, Lu JJ, Ma X, Wang B, Hong X, Li X, Li J. Combined chemoradiation for the management of nasal natural killer (NK)/T-cell lymphoma: elucidating the significance of systemic chemotherapy. Oral Oncol. 2008; 44:23-30.

24. Wang B, Lu JJ, Ma X, Guo Y, Lu H, Hong X, Li J. Combined chemotherapy and external beam radiation for stage IE, IIE natural killer T-cell lymphoma of nasal cavity. Leuk Lymphoma. 2007; 48:396-402.

25. Li YX, Wang H, Jin J, Wang WH, Liu QF, Song YW, Wang ZY, Qi SN, Wang SL, Liu YP, Liu XF, Yu ZH. Radiotherapy alone with curative intent in patients with stage I extranodal 
nasal-type NK/T-cell lymphoma. Int J Radiat Oncol Biol Phys. 2012; 82:1809-1815.

26. Yang Y, Cao JZ, Lan SM, Wu JX, Wu T, Zhu SY, Qian LT, Hou XR, Zhang FQ, Zhang YJ, Zhu Y, Xu LM, Yuan ZY, et al. Association of Improved Locoregional Control With Prolonged Survival in Early-Stage Extranodal Nasal-Type Natural Killer/T-Cell Lymphoma. JAMA Oncol. 2017; 3:83-91.

27. Winter JN. Defining the role of immunotherapy and radioimmunotherapy in the treatment of low-grade lymphoma. Curr Opin Hematol 2007; 14:360-368.

28. Wu X, Li P, Zhao J, Yang X, Wang F, Yang YQ, Fang F, $\mathrm{Xu}$ Y, Zhang H, Wang WY, Yi C. A clinical study of 115 patients with extranodal natural killer/T-cell lymphoma, nasal type. Clin Oncol (R Coll Radiol). 2008; 20:619-625.

29. Liao JB, Chuang SS, Chen HC, Tseng HH, Wang JS, Hsieh PP. Clinicopathologic analysis of cutaneous lymphoma in taiwan: a high frequency of extranodal natural killer/t-cell lymphoma, nasal type, with an extremely poor prognosis. Arch Pathol Lab Med. 2010; 134:996-1002.

30. Liang R, Wang Z, Bai QX, Gao GX, Yang L, Zhang T, Gu HT, Dong BX, Shu MM, Hao CX, Zhang N, Chen XQ. Natural Killer/T Cell Lymphoma, Nasal Type: A Retrospective Clinical Analysis in North-Western China. Oncol Res Treat. 2016; 39:45-52.

31. Liang DN, Yang ZR, Wang WY, Zhao S, Yang QP, Tang Y, Bi CF, Liu WP. Extranodal nasal type natural killer/T-cell lymphoma of testis: report of seven cases with review of literature. Leuk Lymphoma. 2012; 53:1117-1123.

32. Ji J, Liu T, Xiang B, Liu W, He C, Chen X, Li J, Chang H, Dai Y, Dong T. A study of gemcitabine, 1-asparaginase, ifosfamide, dexamethasone and etoposide chemotherapy for newly diagnosed stage IV, relapsed or refractory extranodal natural killer/T-cell lymphoma, nasal type. Leuk Lymphoma. 2014; 55:2955-2957.

33. Takahashi E, Ohshima K, Kimura H, Hara K, Suzuki R, Kawa K, Eimoto T, Nakamura S. Clinicopathological analysis of the age-related differences in patients with Epstein-Barr virus (EBV)-associated extranasal natural killer (NK)/T-cell lymphoma with reference to the relationship with aggressive NK cell leukaemia and chronic active EBV infection-associated lymphoproliferative disorders. Histopathology. 2011; 59:660-671.

34. Chen Y, Zheng X, Chen B, Yang X, Zheng J, Zheng Z, Yang T, Liu T, Hu J. The clinical significance of EpsteinBarr virus DNA in peripheral blood mononuclear cells in patients with non-Hodgkin lymphoma. Leuk Lymphoma. 2017; 58:2349-2355.
35. Ding W, Wang J, Zhao S, Yang Q, Sun H, Yan J, Gao L, Yao W, Zhang W, Liu W. Clinicopathological study of pulmonary extranodal nature killer/T-cell lymphoma, nasal type and literature review. Pathol Res Pract. 2015; 211:544-549.

36. Suzuki R. Treatment of advanced extranodal NK/T cell lymphoma, nasal-type and aggressive NK-cell leukemia. Int J Hematol 2010; 92:697-701.

37. Tse E, Kwong YL. The diagnosis and management of NK/ T-cell lymphomas. J Hematol Oncol. 2017; 10:85.

38. Tse E, Kwong YL. Diagnosis and management of extranodal NK/T cell lymphoma nasal type. Expert Rev Hematol. 2016; 9:861-871.

39. Jiang L, Li SJ, Jiang YM, Long JX, Wang RS, Su J, Zhang Y. The significance of combining radiotherapy with chemotherapy for early stage extranodal natural killer/Tcell lymphoma, nasal type: a systematic review and metaanalysis. Leuk Lymphoma. 2014; 55:1038-1048.

40. Kim BS, Kim TY, Kim CW, Kim JY, Heo DS, Bang YJ, Kim NK. Therapeutic outcome of extranodal NK/T-cell lymphoma initially treated with chemotherapy--result of chemotherapy in NK/T-cell lymphoma. Acta Oncol. 2003; 42:779-783.

41. Chauchet A, Michallet AS, Berger F, Bedgedjian I, Deconinck E, Sebban C, Antal D, Orfeuvre H, Corront B, Petrella T, Hacini M, Bouteloup M, Salles G, Coiffier B. Complete remission after first-line radio-chemotherapy as predictor of survival in extranodal NK/T cell lymphoma. J Hematol Oncol. 2012; 5:27.

42. Kim GE, Lee SW, Chang SK, Park HC, Pyo HR, Kim JH, Moon SR, Lee HS, Choi EC, Kim KM. Combined chemotherapy and radiation versus radiation alone in the management of localized angiocentric lymphoma of the head and neck. Radiother Oncol. 2001; 61:261-269.

43. Kim K, Chie EK, Kim CW, Kim IH, Park CI. Treatment outcome of angiocentric T-cell and NK/T-cell lymphoma, nasal type: radiotherapy versus chemoradiotherapy. Jpn J Clin Oncol. 2005; 35:1-5.

44. You JY, Chi KH, Yang MH, Chen CC, Ho CH, Chau WK, Hsu HC, Gau JP, Tzeng CH, Liu JH, Chen PM, Chiou TJ. Radiation therapy versus chemotherapy as initial treatment for localized nasal natural killer (NK)/T-cell lymphoma: a single institute survey in Taiwan. Ann Oncol. 2004; 15:618-625.

45. Cronin KA, Ries LA, Edwards BK. The Surveillance, Epidemiology, and End Results (SEER) Program of the National Cancer Institute. Cancer. 2014; 120: 3755-3757. 